\title{
An Empirical Analysis of Children's After School Out-of-Home Activity-Location Engagement Patterns and Time Allocation
}

\author{
Rachel B. Copperman
}

The University of Texas at Austin

Dept of Civil, Architectural \& Environmental Engineering

1 University Station C1761, Austin, TX 78712-0278

Tel: (512) 471-4535; Fax: 512-475-8744

Email: RCopperman@mail.utexas.edu

and

Chandra R. Bhat*

The University of Texas at Austin

Dept of Civil, Architectural \& Environmental Engineering

1 University Station C1761, Austin, TX 78712-0278

Tel: (512) 471-4535; Fax: (512) 475-8744

Email: bhat@mail.utexas.edu

*corresponding author 


\begin{abstract}
Children are an often overlooked and understudied population group, whose travel needs are responsible for a significant number of trips made by a household. In addition, children's travel and activity participation during the post-school period have direct implication for adults' activity-travel patterns. A better understanding of children's after school activity-travel patterns and the linkages between parents and children's activity-travel needs is necessary for accurate prediction and forecasting of activity-based travel demand modeling systems. In this paper, data from the 2002 Child Development Supplement (CDS) of the Panel Study of Income Dynamics (PSID) is used to undertake a comprehensive assessment of the post-school out-of-home activitylocation engagement patterns of children aged 5 to 17 years. Specifically, this research effort utilizes a multinomial logit model to analyze children's post-school location patterns, and employs a multiple discrete-continuous extreme value (MDCEV) model to study the propensity of children to participate in, and allocate time to, multiple activity episode purpose-location types during the after-school period. The results show that a wide variety of demographic, attitudinal, environmental, and others' activity-travel pattern characteristics impact children's after school activity engagement patterns.
\end{abstract}

Keywords: children's activity patterns, children's time-use, discrete-continuous model systems, post-school travel, and activity-based travel analysis 


\section{INTRODUCTION}

More daily trips in the United States are undertaken during the 3-4 pm hour of the day than during any other hour, and $43.1 \%$ of all daily trips are made between 2-8pm (USDOT, 2001). This peak in trips during the afternoon period can be attributed in part to children's after school activity and travel patterns, suggesting that children's travel needs play a role in the congestion that plagues many of our nation's cities. In fact, a study examining data from the 1995 National Personal Travel Survey found that approximately $30 \%$ of children do not go directly home afterschool, and instead travel from school to participate in other activities. In addition, approximately $40 \%$ of children make an additional trip after returning home from school (Clifton, 2003).

Children's travel and activity participations during the post-school period, in addition to contributing directly to afternoon trips, also have implications for adults' activity-travel patterns. For instance, Reisner (2003) found that parents spend considerable time and resources transporting children to and from after-school activities, while other studies have found that parents, especially mothers, make frequent stops on the commute to work and to, or from, nonwork activities due to the need to escort children to activities (Hensher and Reyes, 2000; McGuckin and Murakami, 1999; Wallace et al., 2000; McGuckin and Nakamoto, 2004). It is these activities, and their location, that determine the temporal and spatial dimensions of adults' serve-passenger trips and joint activities. Thus, a better understanding of children's after-school activity-travel patterns, and the linkages between parents and children's activity-travel needs, is necessary for accurate prediction and forecasting of activity-based travel demand modeling systems (see Copperman and Bhat, 2007 for an elaboration of this point).

In contrast to the need to examine and model children's activity-travel patterns, existing activity-based research and modeling systems have almost exclusively focused their attention on the activity-travel patterns of adults (see Bradley and Bowman, 2006). This motivates the objective of the current research study, which is to develop and apply an approach to characterize the post-school activity-travel patterns of children. In doing so, one has to consider several dimensions of children's post-school activity-travel patterns, as we discuss next. 


\subsection{Representation of Children's Post-school Activity-travel Patterns}

At a fundamental level, the complete characterization of a child's post-school activity-travel pattern entails the full spatial, temporal, activity purpose, and travel mode attributes of each

activity episode undertaken after school, as well as the sequencing of all activity episodes (inhome as well as out-of-home). Due to the large number of attributes across activity episodes and the large number of possible choice alternatives for each attribute, the joint modeling of all attributes of all episodes is infeasible. Consequently, a representation framework that is feasible to implement from a practical standpoint is required.

We propose a three-tiered representation framework for children's post-school activitytravel patterns. At the first level, we propose the examination of the overall progression of a child's pattern in terms of three activity-travel dimensions: (1) the broad characterization of the activity episode location immediately following the end of classes at school (i.e., whether the child goes home, stays at school, or goes to a non-home location at the end of classes), (2) the broad characterization of the episode locations immediately following any stay at school episode (i.e., whether the child goes home or goes to another location after staying at school), and (3) the post-home arrival activity-travel pattern (whether a child stays at home after arriving home or pursues one or more non-home activities after returning home). Figure 1 shows the seven possible patterns based on these three dimensions. The patterns are numbered at the bottom and correspond to the following:

1. Return directly home from school and stay at home,

2. Return directly home from school and go back out,

3. Stay at school after school, then return home and stay home,

4. Stay at school after school, then return home and go back out,

5. Stay at school after school, then go elsewhere,

6. Go elsewhere after school, then return home and stay home, and

7. Go elsewhere after school, then return home and go back out.

For Patterns 2, 4, and 7, note that the "go back out" activity instances include all episodes until the final return home at the end of the day. Thus, Pattern 2 may represent a child who goes back out to do personal business after returning home directly from school, then returns home from the personal business episode, and then goes back out again to recreate. The personal business episode, the home return, and the recreation episode all are contained in the "go back 
out" activity instance of Pattern 2. For Pattern 5, one could extend the pattern to a return home followed by a "go elsewhere" activity instance, but such an extended pattern rarely occurs. So, we confine the analysis to a "stay at school" activity instance followed by one or more episodes pursued at one or more non-home locations (within the "go elsewhere" box) and a return home/stay home episode.

At the second level of the representation framework, the emphasis is on analyzing the attributes of each out-of-home activity episode within the "stay at school", "go back out", and "go elsewhere" activity instances of the child's chosen pattern of Figure 1 (these instances are identified by the dark boxes in Figure 1, and have been numbered within the dark boxes). The attributes of the out-of-home activity episode participations include activity purpose, duration, and location type, where the location type attribute is applicable only for the episodes in the "go back out" and "go elsewhere" activity instances. It should also be noted that, while any activity purpose taxonomy may be used for episodes at this level, the one adopted in the empirical analysis of the current paper includes seven activity purposes - organized activities, personal business, recreation, social, childcare, meals, and other. These activity purposes were determined based on the classification scheme adopted in the survey that formed the basis for the empirical analysis, as well as on ensuring that a reasonable number of children actually chose each activity purpose in the sample. Similar considerations led to the use of four location types for activity episode participations in the "go back out" and "go elsewhere" activity instances - school, someone else's home, restaurant, and other location types. ${ }^{1}$ Note that a child may participate in multiple out-of-home episodes of different purposes at each of the activity instances (dark boxes of Figure 1), and this is accommodated at this second representation level (we will refer to this second level as the activity episode purpose-location type level in the rest of this paper).

The third and final representation level entails the sequencing of the out-of-home episodes within each of the "stay at school", "go elsewhere" and "go back out" activity instances, along with the precise spatial location, time-of-day, and travel mode attributes of each episode (for brevity, we will refer to this third level as the episode sequencing level). This level also determines if there are any in-home episodes interspersed between out-of-home activity episodes

\footnotetext{
${ }^{1}$ It is possible to have "school" as an activity location alternative for each of the "go back out" and "go elsewhere" instances. For example, consider the "go elsewhere" instance (box number 5) of Pattern 6 in Figure 1. If a child leaves school to participate in a recreation activity at someone else's home, next returns back to school for a recreational event, and finally goes home and stays there, the child would fall in Pattern 6 and the "go elsewhere" instance would include two episodes - "recreation at someone else's home" and "recreation at school".
} 
of each activity instance. At the end of this three-level representation, one essentially has characterized the complete post-school activity-travel pattern of a child. ${ }^{2}$

\subsection{Current Study in the Context of Earlier Studies}

The focus of the current study is on the first two levels - the pattern level and the activity episode purpose-location type level - of the three-tiered representation just discussed. In doing so, we build upon several earlier studies that have examined one or more dimensions of children's activity participation within these two levels. We provide a brief overview of these studies below.

In the context of the pattern level of our proposed representation framework, Clifton (2003) and McDonald (2005) descriptively examined the percentage of students who returned directly home from school, made stops on the way home from school, and who went back out after returning home. But these studies did not estimate models to study the factors affecting a child's choice of post-school activity pattern. These studies also did not examine the activity location instance (whether at school or elsewhere) of the activities pursued immediately after school, nor did they consider all possible after school patterns.

Several studies have examined children's participation and duration of participation in activities by purpose during the after school period. These studies contribute to the activity episode purpose-location type level of our proposed framework, and can be grouped into three areas: (1) Studies that examine a specific type of after school activity such as leisure participation or structured activities (see, for example, Huebner and Mancini, 2003; Sener et al., 2008; and Harrell et al., 1997), (2) Descriptive time-use studies which examine children's overall daily participation rate and duration of participation in a variety of activities (see, for example, Hofferth and Sandberg, 2001; Copperman and Bhat, 2007; Stefan and Hunt, 2006; and Larson and Verma, 1999), and (3) Studies that examine the factors affecting after-school daily or weekly activity participation within a select age or population group (see, for example, Zill et al., 1995; Posner and Vandell, 1999; and Shann, 2001). The studies identified above, while providing important insights, are focused on overall time-use in activities after school, rather than on the sequencing of activity episodes and duration/location type of individual episodes.

\footnotetext{
${ }^{2}$ If one desires, it is also possible to detail the in-home activity episode attributes in a manner similar to level 2 for the out-of-home episodes. Then, all the in-home and out-of-home episodes can be sequenced in level 3. In this paper, we do not consider the in-home episodes of children.
} 
An important aspect of the current study is the emphasis on the location dimension of activity episode participation. In particular, we recognize school as an important location for after-school activities. There are three reasons to explicitly consider school as a possible location for children's post-school activities. First, school is a popular activity location for after school activities. A study by Copperman and Bhat (2007) found that over $20 \%$ of children participate in activities at school during the post-school period. In addition, Hofferth and Jankuniene (2001) found that $8 \%$ of children, aged 5 to 13 , remain at school directly after school. Second, if a child remains at school after classes, he/she may not have the option to take the school bus home since the school bus normally departs immediately at the end of classes. Previous research on school mode choice does not recognize this issue as a factor in mode choice decisions (see Yarlagadda and Srinivasan, 2007 for a review of school mode choice studies). Third, the explicit consideration of the propensity of children to participate in activities at school provides an improved characterization of children's post-school activity-travel pattern.

Notwithstanding the importance of the location dimension for after-school activities in general, and the importance of considering school as a potential location in particular, there has been only one study by Hofferth and Jankuniene (2001) that has explicitly examined children's activity location directly after school. However, this earlier study is descriptive in nature and does not consider the location of activity episodes beyond that pursued immediately after school (i.e., it does not consider the location of out-of-home episodes pursued after a child returns home from school or from the non-school location activity episode(s) pursued immediately after school).

The rest of this paper is structured as follows. Section 2 describes the analysis framework and model formulation. Section 3 discusses the data source and sample formation, and presents the pattern level and activity episode purpose-location type level descriptive statistics. Section 4 presents the empirical analysis results. Finally, Section 5 concludes the paper.

\section{ANALYSIS FRAMEWORK}

In this section, we present the alternatives and the model structures used for each of the pattern and activity episode purpose-location type models. 


\subsection{Pattern Model}

As indicated earlier in Section 1.1, there are seven possible alternatives for a child's post-school activity-travel pattern (see Figure 1). We considered a simple multinomial logit model as well as different two-level nesting structures to analyze the choice among these seven alternatives. However, the nesting structures were not supported by the data, either because the log-sum parameter exceeded one or was not significantly less than one. Thus, the final model structure for location class sequencing in the current paper corresponded to a simple multinomial logit (MNL) model.

\subsection{Activity Episode Purpose-Location Type Model}

This model examines the activity episode purpose-location type attributes, as well as the activity duration, for each out-of-home episode within the "stay at school", "go back out", and "go elsewhere" instances, conditional on the child's pattern. As indicated in Section 1.2, we identify seven activity purposes. Further, for episodes in the "stay at school" instance (box 2 in Figure 1), there is only one location type, which is "school". Thus, for the episodes in this box, the only available activity episode purpose-location type combinations are the seven activity purposes. For the out-of-home episodes in the "go back out" and "go elsewhere" boxes, there can be four location types - school, someone else's home, restaurant, and other. Technically, then, one could have 28 activity purpose-location type combinations for each of these two box types. However, many of these combinations seldom occur in the sample. For instance, consider "personal business" episodes within the non-stay at school instances (boxes 1, 3, 4, 5 and 6 of Figure 1). Almost all of these episodes occur at a location other than at someone else's home, school, or at a restaurant. Thus, we use a single "personal business" alternative without further partitioning this by location type.

After careful consideration of the number of episodes of each possible activity episode purpose-location type combination in the sample, we identified a total of twelve alternatives for the empirical analysis: (1) Organized activities at school, (2) Organized activities at a location other than school, (3) Personal Business, (4) Recreation at someone else's home, (5) Recreation at school, (6) Recreation at other locations, (7) Social at someone else's home, (8) Social at locations other than someone else's home, (9) Childcare, (10) Meals at restaurant, (11) Meals at 
a location other than a restaurant (over $70 \%$ of such episodes are at someone else's home), and (12) Other.

As children can engage in multiple activity episode purpose-location type combinations within each of the activity instances (boxes labeled 1 through 6) in Figure 1, and allocate time to each of the activity episode purpose-location types, a multiple discrete-continuous extreme value (MDCEV) model formulation is adopted (see Bhat, 2005 and Bhat, 2008). While separate MDCEV models can be estimated for each activity instance, we estimate a single universal MDCEV model for efficiency considerations. In doing so, however, we use variables that identify the activity instance, since some activity episode purpose-location type combinations are more likely to occur in certain activity instances than others (for example, "organized activities at school" are more likely to occur in the "stay at school" activity instance than in other activity instances). Also, note that some alternatives may not be available for episodes in some activity instances, which we recognize by considering only the feasible alternatives for each activity instance (for example, "organized activities at location other than school" or "recreation at other locations" are not feasible alternatives for the "stay at school" box in Figure 1). We next briefly describe the basic MDCEV model structure.

Let $t_{k}$ be the time invested in alternative $k(k=1,2, \ldots, K)$ at each activity instance, where $k$ is an index for the activity episode purpose-location type combinations. Consider the following additive, non-linear, functional form to represent the utility accrued by an individual through time investment in various activity episode purpose-location type combinations at each activity instance (the index for the individual and the activity instance is suppressed in the following presentation) ${ }^{3}$ :

$U(\boldsymbol{t})=\sum_{k=1}^{K} \frac{1}{\alpha_{k}} \exp \left(\beta^{\prime} z_{k}+\varepsilon_{k}\right)\left\{\left(t_{k}+1\right)^{\alpha_{k}}-1\right\}$

$z_{k}$ is a vector of exogenous determinants (including a constant) specific to alternative $k$ (there is no such vector for the first alternative because only differences in utilities matter, as shown later). The term $\exp \left(\beta^{\prime} z_{k}+\varepsilon_{k}\right)$ represents the random marginal utility of one unit of time investment in alternative $k$ at the point of zero time investment for the alternative. This can be observed by

\footnotetext{
${ }^{3}$ Several other additive, non-linear, utility forms, as proposed by Bhat (2008), were also considered. However, the one provided below was the best form in the empirical analysis of the current paper.
} 
computing the partial derivative of the utility function $U(t)$ with respect to $t_{k}$ and computing this marginal utility at $t_{k}=0$ (i.e., $\left.\partial U(t) /\left.\partial t_{k}\right|_{t_{k}=0}\right)$. Thus, $\exp \left(\beta^{\prime} z_{k}+\varepsilon_{k}\right)$ controls the discrete choice participation decision in alternative $k$. We will refer to this term as the baseline preference for alternative $k . \quad \alpha_{k}$ is a satiation parameter whose role is to reduce the marginal utility with increasing consumption of alternative $k$. When $\alpha_{k}=1$ for all $k$, this represents the case of absence of satiation effects. Values of $\alpha_{k}$ closer to zero imply higher satiation (or lower time investment) for a given level of baseline preference.

From the analyst's perspective, individuals are maximizing random utility $U(t)$ at each activity instance subject to the time budget constraint that $\sum_{k} t_{k}=T$, where $T$ is the total time available for children to participate in various activity episode purpose-location types. The optimal time investments $t_{k}^{*}(k=1,2, \ldots, K)$ can be found by forming the Lagrangian function (corresponding to the problem of maximizing random utility $U(\boldsymbol{t})$ under the time budget constraint $T$ ) and applying the Kuhn-Tucker (KT) conditions. After extensive, but straightforward, algebraic manipulations, the KT conditions collapse to (see Bhat, 2008):

$V_{k}+\varepsilon_{k}=V_{1}+\varepsilon_{1}$ if $t_{k}^{*}>0(k=2,3, \ldots, K)$

$V_{k}+\varepsilon_{k}<V_{1}+\varepsilon_{1}$ if $t_{k}^{*}=0(k=2,3, \ldots, K)$, where

$V_{k}=\beta^{\prime} z_{k}+\left(\alpha_{k}-1\right) \ln \left(t_{k}^{*}+1\right)(k=1,2,3, \ldots, K)$.

Assuming that the error terms $\varepsilon_{k}(k=1,2, \ldots, K)$ are independent and identically distributed across alternatives with a type 1 extreme value distribution, the probability that the child allocates time to the first $M$ of the $K$ alternatives (for duration $t_{1}^{*}$ in the first alternative, $t_{2}^{*}$ in the second, $\ldots t_{M}^{*}$ in the $M^{\text {th }}$ alternative) is (see Bhat, 2008):

$$
P\left(t_{1}^{*}, t_{2}^{*}, t_{3}^{*}, \ldots, t_{M}^{*}, 0,0, \ldots, 0\right)=\left[\prod_{i=1}^{M} c_{i}\right]\left[\sum_{i=1}^{M} \frac{1}{c_{i}}\right]\left[\frac{\prod_{i=1}^{M} \varsigma_{i} e^{V_{i}}}{\left(\sum_{k=1}^{K} \varsigma_{k} e^{V_{k}}\right)^{M}}\right](M-1) !
$$


where $c_{i}=\left(\frac{1-\alpha_{i}}{t_{i}^{*}+1}\right)$ and $\varsigma_{k}=1$ if alternative $k$ is available for the activity instance under consideration.

\section{DATA SOURCE AND SAMPLE}

\subsection{Data Source}

The data source for this analysis is the 2002 Child Development Supplement (CDS-II) to the Panel Study of Income Dynamics (PSID). The PSID is a longitudinal study that collected demographic, employment and health information from a national sample of individuals and households. The CDS-II surveyed over 2,500 children through health and achievement test surveys, primary caregiver and child interviews, and a two-day time-use diary - one for a weekday and the other for a weekend day. The time-use diary collected information on the type, number, duration, and location of activities for each 24-hour survey day beginning at midnight. Paper diaries were mailed to children, filled out on or around the activity day, and then retrieved and reviewed by an interviewer either by phone or in person. Older children and adolescents were expected to fill out their own diary, while primary caregivers aided younger children.

\subsection{Sample Formation}

The process of generating the sample for analysis involved several steps. First, only individuals aged five through seventeen who were enrolled in primary or secondary school and who attended school on the activity day were considered for the analysis. Also, only children who filled out at least a weekday diary and provided complete supplemental information were included. The final sample for analysis includes 2,065 children. Second, activity episode purposes were reclassified from the 365 original types into 8 activity purposes: (1) School, (2) Organized activities (i.e. lessons, meetings, and clubs), (3) Personal business (i.e. shopping, obtaining services, paying bills, writing e-mails or letters), (4) Recreation (i.e. unorganized hobbies and sports, outings, reading, playing, TV viewing, and music), (5) Social (including conversations, being intimate, parties, visiting, and religious services), (6) Childcare (i.e. daycare, being babysat) (7) Meals (including snacks), and (8) Other. Third, activity episode locations were collapsed into five location types: (1) Home, (2) School, (3) Someone else's home (including other parents' home), (4) Restaurant, and (5) Other. Fourth, out-of-home activity instances were identified by re- 
organizing the activity episodes based on location of performance (in-home or out-of-home), followed by the tracing of the sequence of out-of-home and in-home episodes. Fifth, the time investments across all activity episode purpose-location types in an activity instance were aggregated to obtain total activity instance time investments. Thus, for each individual, there is a complete profile of multiple activity episode purpose-location type participation at each activity instance point. Finally, individual and household demographic and socio-economic characteristics, as well as attitude and environment variables, were appended to the activity and time use data set to compile a comprehensive database suitable for modeling children's activitylocation engagement patterns as a function of observed characteristics.

\subsection{Pattern and Activity Episode Purpose-Location Type Statistics}

Figure 1 provides statistics on the percentage of children in each pattern. As can be observed, $65.6 \%$ of all children go directly home after school (corresponding to Patterns 1 and 2), 13.9\% stay at school immediately after school (corresponding to Patterns 3, 4, and 5), and 20.5\% go elsewhere immediately after school (corresponding to Patterns 6 and 7). Hofferth and Jankuniene (2001), McDonald (2005), and Clifton (2003) also find similar results. Overall, over 30\% of children do not go home directly after school, and a majority of children (57.7\%) participate in at least one out-of-home activity after school. These findings reinforce the notion that children's activities are responsible for a significant number of household trips.

Table 1 presents the number and percentage of activity episode purpose-location type participations within each activity instance (the percentages are computed row-wise, so that for each activity episode purpose-location type combination, the percentages sum to 100 across all activity instance columns). By definition, the "Stay at school" activity instance (box 2 in Figure 1) does not include some activity episode purpose-location type combinations (see Columns 5 and 6 of Table 1).

There are several interesting insights that may be drawn from Table 1. First, the majority of organized activities at school take place directly after school (i.e., in activity instance "stay at school"), while the majority of organized activities at locations other than school are undertaken by children who first return directly home from school (i.e., in box 1 of Figure 1). Second, personal business is most likely to be undertaken after returning home directly from school (in box 1 of Figure 1) and directly after school (in box 5 of Figure 1). It is quite possible that these 
statistics indicate children accompanying an adult on the adult's errands, rather than a child undertaking his/her own personal business needs. Third, among all activity episode purposelocation type alternatives, children participate most in "recreation at someone else's home" (see the second column of Table 1 labeled "Total"; the row labeled "Other" has a higher number than "Recreation at someone else's home", but is a combination of several activity episode purposelocation types). The majority of participations in "recreation at someone else's home" is undertaken immediately after-school (in box 5 of Figure 1). The finding that many children travel to a friend's or relative's home immediately after school, instead of to their own home, emphasizes the importance of considering inter-household interactions in school and post-school mode and activity choice models. Finally, over 95\% of "childcare" episodes occur immediately after school, either at school or at another location. This finding is logical, since it is during the afternoon period, when parents are still at work, that a child needs non-parent adult supervision.

Table 2 presents additional descriptive statistics on participation in the activity episode purpose-location types, including (1) the percentage of activity episode purpose-location type cases that are participated alone within an activity instance, (2) the percentage participated in combination with other episode types, (3) the total number of each episode type across all activity instances, and (4) the mean duration of participation in each activity episode purposelocation type alternative, conditional on participation in that alternative. The findings reveal that organized activities and childcare are the activities that are most likely to be undertaken in isolation (see column 2 of Table 2). In combination with the findings from Table 1, the implication is that many children stay at school for the sole purpose of participating in organized activities or daycare, or make a single one stop tour immediately after school or from home to undertake these activities. On the other hand, social activities and meals at a location other than a restaurant are most likely to be undertaken in conjunction with other episode types. It is also noteworthy that "meals at restaurant" have a much higher solo participation rate and duration of participation compared to meals at other locations. This finding reinforces the importance of examining episode location in addition to activity type. With regard to duration of participation, not surprisingly, organized activities, recreation, and receiving childcare have the longest duration of participation, while personal business and meals have the shortest duration of participation (see last column of Table 2). 


\section{EMPIRICAL ANALYSIS}

\subsection{Variable Specification}

Discrete choice and MDCEV model specifications were developed and estimated for this study. Several types of variables were considered as determinants of children's activity-travel patterns. Also, different variable specifications and functional forms (e.g., linear and non-linear income and age effects) were attempted to identify the model specification that provided the most intuitively appealing behavioral interpretation and statistical indications. The final set of exogenous variables in the models may be classified into five groups:

1) Child demographics: grade (grade k-4, grade 5-8, and grade 9-12), ethnicity (Caucasian, African American, Hispanic, and other), disabled (whether child is physically or mentally disabled or not), and overweight status (whether child has BMI above 95\% in the child's gender and age group or not).

2) Household demographics: household income (yearly income is less than $\$ 25,000$, $\$ 25,000-\$ 90,000$, or above $\$ 90,000$ ), number of household vehicles, household size, number of adults in household, single child household (whether child is only child in household or not), internet access (whether household has internet or not), single-family home (whether household resides in single-family house or not), primary caregiver (whether primary caregiver is mother, father, grandmother, or other individual), age of primary caregiver, presence of younger siblings, and presence of older siblings.

3) Child's attitude variables: high educational ambition (whether child's preferred education is to attend professional/graduate school or not), gifted program participation (whether child has ever attended a gifted program or not), special education participation (whether child has ever attended special education or not) and sociability (whether child socializes with friends at least once a week or less than once a week).

4) Environment/contextual variables: private school (whether child attends private school or not), neighborhood quality (whether primary caregiver believes neighborhood is a good place to raise a child or not), neighborhood safety (whether primary caregiver believes neighborhood is safe or not), city size (whether child resides in county containing city size over 1 million or not), metropolitan area county (whether child resides in county within a metropolitan area or not), and Friday (whether activity day is Friday or not). 
5) Others' activity-travel patterns: primary caregiver works after school (whether primary caregiver works on activity day later than child finishes school or not), and other caregiver works after school (whether non-primary caregiver works on activity day later than child finishes school or not).

\subsection{Empirical Results}

Model estimation results for the pattern MNL model are presented in Table 3 and the model estimation results for the activity episode purpose-location type participation and time-use MDCEV model are presented in Table 4. The reader should note that the missing variables in Table 3 and Table 4 constitute the base category. For instance, in Table 3, the base category for introducing the grade-level variables is grades k-4, while in Table 4 the base category is grades 5-12. Also, note that some estimates may be the same across different alternatives for a variable, which implies that the coefficient values are not statistically significantly different and have been combined. Finally, the variable effects in Tables 3 and 4 reflect the impacts on the utility of alternatives. If a variable effect does not appear in the row corresponding to an alternative (as reflected by a "--" entry), it implies that the alternative forms the base about which the variable effect on other alternatives is evaluated. For instance, in Table 3, the effect of the "Grade 5 to 8 " variable appears only for sequences 6 and 7, with the effective coefficient for all the other alternatives being zero.

\subsubsection{Pattern Model}

4.2.1.1 Child Demographics The pattern model results in Table 3 indicate that children in grades 5-8 are less likely than children in grades k-4 and grades 9-12 to go elsewhere directly afterschool (see the negative coefficient of -0.6084 for Sequences 6 and 7 in the column labeled "Grades 5 to 8"). Such children are more likely to either go back home or stay at school immediately after school. This result is similar to other studies that found that middle school children make the least number of post-school trips and are the most likely to go straight home from school compared to other age groups (McDonald, 2005; Clifton, 2003). On the other hand, adolescents in grades 9 to 12 are more likely than other children to go back out after returning directly home from school, and are more likely to stay at school after-school. This may reflect the higher availability of extracurricular activities at high school relative to middle and 
elementary school, as well as the greater freedom to remain after school at school to socialize or study with friends.

Not surprisingly, children who are mentally or physically disabled desist from undertaking out-of-home activities after returning directly home from school. Children who are overweight partake less than their non-overweight peers in out-of-home activities after returning home. In the face of increasing levels of obesity in children, this result warrants more attention and research.

4.2.1.2 Household Demographics It is a very intuitive and interesting finding that children living in high income households and/or in households with several vehicles are more likely to go elsewhere directly after school and to participate in additional out-of-home activity episodes after returning home. This result reinforces the notion that children in households with higher income and higher number of vehicles make more daily trips (McDonald, 2005). In addition, this finding may shed additional light on why households with higher income and higher number of vehicles are more likely to drive their children from school (Yarlagadda and Srinivasan, 2007; Bradshaw and Atkins, 1996; Mackett et al., 2002). However, further research should be undertaken to disentangle the causation effects to understand whether children are being driven from school because they are undertaking out-of-home activities directly after school, or whether they make a stop on the way home from school because they are traveling by car.

With regard to household composition, if the child is an only child, then s/he is more likely than other children to stay at school after school or go elsewhere directly after school. The latter result may be a reflection of having more opportunities to participate in out-of-home activities, since the child does not have to compete with other children for parental escorting. On the other hand, the results also indicate that children in households with several adults are less likely to go elsewhere directly after school.

Interestingly, if a child lives in a household with internet access, the child has a high propensity to go home directly after school and remain at home for the remainder of the day. This may be due to the use of the internet for homework and socializing, as a substitute for studying elsewhere or socializing in person. Another notable finding is that children who live in single-family dwelling units tend to go elsewhere after school and then pursue additional out-ofhome activities. While this result should be further examined, this variable may be a proxy for 
neighborhood characteristics that are not directly examined in this study. The next variable effect in Table 3 indicates that if the father is the primary caregiver, then the child is more likely to go elsewhere after school and then stay home for the rest of the evening. Finally, in the group of household demographics, if a child has older siblings in the household, the child is more inclined to go elsewhere directly after school and go back out after returning home. This result may be either due to the older siblings taking on the escorting responsibilities for their younger sibling, or the younger sibling accompanying the older sibling on the older sibling's activities.

4.2.1.3 Child's Attitudes Children who have high educational ambition tend to stay at school after school. Similarly, children who have ever been in a gifted program are more likely to stay at school after school or go elsewhere directly after school. Further research should be undertaken to determine whether these children choose to take part in more after school activities because they have high educational ambitions or whether the involvement in after school activities influence their educational ambitions. If the latter, it would suggest the development of policies and campaigns to encourage more after school activities. Children who socialize with friends at least once a week outside of school are positively predisposed toward going elsewhere after staying at school or after returning home. By nature, these children may have a strong desire to undertake out-of-home activities, so they can interact more with friends and peers.

4.2.1.4 Environment/Contextual Variables Children who attend private school are likely to go back out after returning directly home from school or to stay at school after school. Private schools may provide more after-school programs and extracurricular activities at school, compared to public schools. The results also indicate that children who live in high quality neighborhoods tend to return home directly and then go back out. Children who live in safe neighborhoods are more likely to stay at school after school and then go elsewhere. In addition, if a child lives in county containing a city size over 1 million, s/he is less likely to go elsewhere after school and then return home and go back out. The above three results need further exploration. Finally, if it is a Friday, children have an inclination to go back out after returning home or go elsewhere after staying at school. This is to be expected, since children are likely to be allowed to participate in more activities out of home in the evening when not faced with the constraint of going back to school the next day. 
4.2.1.5 Others' Activity-Travel Patterns As expected, children whose primary caregivers are working after the end of school tend to stay at school after school or go elsewhere directly after school. If a child's non-primary caregiver works after school, then a child is more likely to stay at school after school and then return home and go back out.

\subsubsection{Activity Episode Purpose-Location Type Model}

Table 4 presents the results of the activity episode purpose-location type model, which are discussed by variable group below. The estimates presented in the table refer to the $\beta$ vector in Equation (1).

4.2.2.1 Child Demographics Children in kindergarten through fourth grades are more likely than other children to participate in personal business activities, recreation activities, childcare, and meals at locations other than restaurant. The first result is intuitive, since younger children are likely to accompany their parents on errands and, therefore, it is the parent's personal business activity in which a child is likely participating. The higher propensity of younger children to partake in recreational activities is perhaps because of more leisure time availability, since older children may participate in paid work and spend more time on homework and studying (Hofferth and Sandberg, 2001; O'Brian and Gilbert, 2003; McDonald, 2005). The result that younger children are much more likely to participate in childcare compared to older children supports the results found in other studies (see, Copperman and Bhat, 2007, Hofferth and Sandberg, 2001; McDonald, 2005; Hofferth and Jankuniene, 2001).

The child demographic effects also reveal that ethnicity is a significant factor in episode type participation. Caucasian children are more likely to undertake personal business activities and recreation at school, while Hispanic children are more likely to pursue recreation at other locations and African-American children are less likely to eat out at restaurants (see Sener and Bhat, 2007 for similar results). Of course, it is important to disentangle whether it is truly race and culture that is contributing to differences in time-use in different kinds of activity episode purpose-location types, or whether it is a proxy reflection of differences in activity opportunities across different schools and neighborhoods. 
4.2.2.2 Household Demographics Not surprisingly, children living in high income households have a higher tendency to eat out during the post-school period relative to children in low income households (see, also, McDonald, 2005). The household size and "only child" variable effects indicate that single children with several adults in the household are predisposed toward undertaking personal business activities. Children living in households with internet access tend to undertake organized activities, if they participate in out-of-home activities at all. Perhaps this can be attributed to better awareness of organized activity opportunities through the internet. Children living in single-family dwelling units are more likely to undertake organized activities and recreation at non-school locations. Again, the single family dwelling unit variable may be a proxy for neighborhood characteristics that are not directly examined in this study. Interestingly, children whose grandparent is the primary caregiver have a higher propensity to undertake recreation at locations other than school and someone else's home. Also, as the age of the primary caregiver increases, the less likely a child is to partake in, and spend time in, recreation at someone else's home. A similar result is obtained for children with younger siblings. On the other hand, if a child has an older sibling in the household, the child is more inclined to pursue organized activities at locations other than school and recreation activities at locations other than someone else's home and school. Children who have older siblings may be more involved in non-school activities because they accompany their siblings on the older sibling's activities.

4.2.2.3 Child's Attitudes The child's attitude variables reveal that children who have high educational ambitions have a lower propensity to pursue personal business activities after school. These children may be choosing (or their parents may be allowing them) to spend their time on educational activities, such as studying, instead of on errands. Also, children who have ever been in a gifted program are less likely to attend childcare, while children who have been in special education are predisposed toward undertaking personal business activities. This latter result is quite intuitive, since these children may need extra care and so are more likely to accompany their parents on errands instead of participating in other activities independently or staying home alone. Finally, children who socialize with their friends at least once a week are more likely to pursue organized activities, perhaps because organized activities offer the opportunity to meet new people and socialize. 
4.2.2.4 Environment/Contextual Variables The results show that children attending private school have a higher tendency relative to other children to undertake organized activities at locations other than school. Parents who send their children to private school may also have the desire to provide additional extracurricular activities for their children. Also, children who reside in a metropolitan area county are more likely to receive childcare and eat meals out-ofhome. This finding may reflect the differences in availability of childcare services and restaurants between metropolitan and non-metropolitan areas. Finally, the day of week effect reveals lower levels of participation in organized activities on Friday.

4.2.2.5 Others' Activity-Travel Patterns The effect of others' activity-travel patterns indicate, not surprisingly, that if a child's primary caregiver works during the after school period, the child is less likely to recreate at someone else's home and more likely to attend daycare. Interestingly, if the non-primary caregiver works after school, then a child is more likely to participate in organized activities.

4.2.2.6 Activity Instance Variables Activity instance variables were added as independent variables in the activity episode purpose-location type model to accommodate variations in episode type participation based on activity instance. The results indicate that children staying at school after school (box 2 of Figure 1) are positively predisposed to spend time in organized activities, recreation, social activities, and childcare. Children who stayed at school after school are most likely to pursue personal business activities during any additional out-of-home tours from home (box 3 of Figure 1). On the other hand, children who go elsewhere directly after school (box 5 of Figure 1) are most likely to receive childcare or eat meals at a location other than a restaurant, and are less likely to undertake organized activities, recreation at school, social at a location other than someone else's home, and meals at a restaurant. The finding that children are most likely to attend childcare at school or directly after school at another location corroborates the results of the descriptive statistics of Table 2. Finally, children who complete additional tours after coming home from participating in non-school out-of-home activities directly after school (box 6 of Figure 1) tend to pursue organized activities, personal business, recreation at school, and social at someone else's home. Overall, these results underscore the 
different propensities to participate in diverse activity episode purpose-location type combinations at various points in the post-school period.

4.2.2.7 Baseline Preference Constants The baseline preference constants (see second to last column of Table 4) do not have any substantive interpretations. They capture generic tendencies to participate in each activity episode purpose-location type alternative as well as accommodate the range of the age and household size variables in the model.

4.2.2.8 Satiation Parameters The final column of Table 4 presents the satiation parameter $\left(\alpha_{k}\right)$ estimates for the activity episode purpose-location type MDCEV model. The t-statistics for the $\alpha_{k}$ parameters have been computed with respect to a value of 1 (i.e., for the null hypothesis that $\alpha_{k}=1$ for each $k$ ). These t-statistics indicate that the satiation parameters are significantly different from 1 for all activity episode purpose-location types except organized activities at school, thereby indicating satiation effects in the duration of episodes. Note that, as indicated earlier, values of $\alpha_{k}$ farther away from one and closer to zero imply higher satiation (or lower time investment) for a given level of baseline preference.

The satiation effect is equal to 1 for organized activities at school, indicating that once children begin participation in organized activities at school, they will continue to participate in only that activity and spend a substantial duration in the activity. This is consistent with the descriptive statistics in Table 2. At the other end, meals at locations other than a restaurant have the highest satiation effects. Again, this result mirrors the findings in Table 2, which indicate that meals at a location other than a restaurant have a high likelihood of being combined with other episodes and have the lowest average duration levels.

\subsection{Likelihood Based Measures of Fit}

The log-likelihood value at convergence of the pattern MNL model is -297.76. The likelihood value for the model with only the constants is -316.81 . The likelihood ratio test for testing the presence of exogenous variable effects is 38.09 , which is larger than the critical $\chi^{2}$ value with 24 degrees of freedom at a .05 level of significance. 
The log-likelihood value at convergence of the final activity episode purpose-location type MDCEV model is -8143.09 . Further, the likelihood value for the model with only the MDCEV baseline preference constants and the satiation parameters is -8673.54. The likelihood ratio test for testing the presence of exogenous variable effects is 1060.90 , which is substantially larger than the critical $\chi^{2}$ value with 50 degrees of freedom at any reasonable level of significance.

\section{CONCLUSION}

Children are an often overlooked and understudied population group, even though children's travel needs are responsible for a significant number of trips made by a household. In addition, children's travel and activity participation during the post-school period have direct implication for adults' activity-travel patterns. A better understanding of children's after school activitytravel patterns and the linkages between parents and children's activity-travel needs is necessary for accurate prediction and forecasting of activity-based travel demand modeling systems.

In this paper, data from the 2002 Child Development Supplement (CDS) of the Panel Study of Income Dynamics (PSID) is used to undertake a comprehensive assessment of the postschool out-of-home activity-location engagement patterns of children aged 5 to 17 . Specifically, this research effort utilizes an MNL model to analyze children's post-school patterns and employs the MDCEV model to study the propensity of children to participate in, and allocate time to, multiple activity episode purpose-location types during the after school period.

There are several important findings from the study. First, over 55\% of children pursue at least one out-of-home activity after school. This result confirms the importance of examining children's post-school activity-travel patterns, since in many cases it is the location and timing of children's activities that are dictating the activity-travel patterns of other household members. Second, organized activities and childcare are most likely to take place at school directly after school. Third, in addition to demographic characteristics, attitudinal, environmental, and others' activity-travel pattern variables impact children's after school activity engagement patterns. These results confirm the importance of going beyond simple analysis of age, gender, and household income level when examining travel behavior, and support the collection of detailed geospatial information and the inclusion of questions on perceptions and attitudes in travel surveys. Finally, participation and time-allocation to episodes of different activity purposes are 
affected by different factors, depending on the location of participation. Therefore, studying the location type of activity participation will contribute to more accurate location modeling within activity-based travel demand modeling systems and should be further explored in future studies.

Overall, the study represents the first formulation and application of a comprehensive econometric framework to consider children's post-school location patterns and participation, and levels of participation, in joint activity and location combinations. Future research should explore inter-household and intra-household interactions by incorporating the dimension of "with whom children are performing activities", as well as the joint trip making characteristics of household and non-household members. 


\section{REFERENCES}

Bhat, C. R. 2005. A Multiple Discrete-Continuous Extreme Value Model: Formulation and Application to Discretionary Time-Use Decisions. Transportation Research Part B, 39(8), 679-707.

Bhat, C. R. 2008. The Multiple Discrete-Continuous Extreme Value (MDCEV) Model: Role of Utility Function Parameters, Identification Considerations, and Model Extensions. Transportation Research Part B, 42(3), 274-303.

Bradley, M. and J. L. Bowman. 2006. A Summary of Design Features of Activity-Based Microsimulation Models for U.S. MPOs. White Paper for the Conference on Innovations in Travel Demand Modeling, Austin, TX, May 2006.

Bradshaw, R., and S. Atkins. 1996. The use of public transport for school journeys in London. Paper presented at the Proceedings of Seminar F: Public Transport Planning and Operations, September 2-6, 1996.

Clifton, K. J. 2003. Independent Mobility among Teenagers: An Exploration of Travel to AfterSchool Activities. Transportation Research Record, 1854, 74-80.

Copperman, R. B. and C. R. Bhat. 2007. An Exploratory Analysis of Children's Daily Time-Use and Activity Patterns Using the Child Development Supplement (CDS) to the US Panel Study of Income Dynamics (PSID). Transportation Research Record, 2021, 36-44.

Harrell, J. S., S. A. Gansky, C. B. Bradley, and R. G. McMurray. 1997. Leisure Time Activities of Elementary School Children. Nursing Research, 46(5), 246-253.

Hensher, D. A., and A. J. Reyes. 2000. Trip chaining as a barrier to the propensity to use public transport. Transportation, 27, 341-361.

Hofferth, S. L. and J. Jankuniene. 2001. Life After School. Association for Supervision and Curriculum Development, 19-23.

Hofferth, S. L. and J. F. Sandberg. 2001. How American Children Spend Their Time. Journal of Marriage and Family, 63, 295-308.

Huebner, A. J. and J. A. Mancini. 2003. Shaping Structured Out-of-School Time Use Among Youth: The Effects of Self, Family, and Friend Systems. Journal of Youth and Adolescence, 32(6), 453-463.

Larson R. W. and S. Verma. 1999. How Children and Adolescents Spend Time Across the World: Work, Play, and Developmental Opportunities. Psychological Bulletin. 125(6), 701-736. 
Mackett, R. L., L. Lucas, J. Paskins and J.Turbin. 2002. Health Benefits of Non-Car Travel by Children. Paper presented at the Hertfordshire County Council Centre of Excellence Conference on 'School and Business Travel Plans', held in Hatfield, 25 November, 2002.

McDonald, N. 2005. Children's Travel: Patterns and Influences. Ph.D. Dissertation, University of California, Berkeley.

McGuckin, N. and E. Murakami. 1999. Examining Trip-Chaining Behavior: A Comparison of Travel by Men and Women. Transportation Research Record, 1693, 79-85.

McGuckin, N. and Y. Nakamoto. 2004. Differences in Trip Chaining by Men and Women. Research on Woman's Issues in Transportation: Report of a Conference. Vol. 2: Technical Papers. Transportation Research Board, Nov. 18-20, 2004. Chicago, Illinois.

O'Brian, C. and R. Gilbert. 2003. Kids on the move in Halton and Peel: Final Report. Report prepared for The Center for Sustainable Transport.

Posner, J. K. and D. L. Vandell. 1999. After-School Activities and the Development of LowIncome Urban Children: A Longitudinal Study. Developmental Psychology, 35(3), 868879.

Reisner, E. 2003. Understanding Family Travel Demands as a Critical Component in WorkFamily Research, Transportation and Land Use Planning. Proceedings of the Academic Work and Family Research Conference, Orlando FL, February 28-March 1, 2003.

Sener, I. N. and C. R. Bhat. 2007. An Analysis of the Social Context of Children's Weekend Discretionary Activity Participation. Transportation, 34(6), p. 697-721.

Sener, I. N., R. B. Copperman, R. M. Pendyala, and C. R. Bhat. 2008. An Analysis of Children's Leisure Activity Engagement: Examining the Day of Week, Location, Physical Activity Level, and Fixity Dimensions. Forthcoming, Transportation.

Shann, M. H. 2001. Students' Use of Time Outside of School: A Case for After-School Programs for Urban Middle School Youth. The Urban Review, 33(4), 339-355.

Stefan, K. J. and J. D. Hunt. 2006. Age-Based Analysis of Children in Calgary, Canada. Presented at the 85th Annual Meeting of the Transportation Research Board, Washington, D.C.

U.S. Department of Transportation (USDOT), Bureau of Transportation Statistics (BTS) (2003). NHTS 2001 Highlights Report, BTS03-05, Washington, DC.

Wallace, B., J. Barnes and G.S. Rutherford. 2000. Evaluating the effects of traveler and trip characteristics on trip chaining, with implications for transportation demand management strategies. Transportation Research Record, 1718, 97-106. 
Yarlagadda, A. K. and S. Srinivasan. 2007. Modeling Children's School Travel Mode and Parental Escort Decisions. Presented at the 86th Annual Meeting of the Transportation Research Board, Washington, D.C.

Zill, N., C. W. Nord, and L. S. Loomis. 1995. Adolescent Time Use, Risky Behavior, and Outcomes: An Analysis of National Data. Report prepared for the Office of Human Services Policy, U.S. Department of Health and Human Services, Washington, D.C. 


\section{LIST OF FIGURES}

Figure 1. Children's Post-School Patterns and Percentage of Children Choosing Each Pattern

\section{LIST OF TABLES}

Table 1. Number and Percentage of Activity Episode Purpose-Location Type at Each Activity Instance

Table 2. Descriptive Statistics of Activity Episode Purpose-Location Type Participation

Table 3. Pattern MNL Model

Table 4. Activity Episode Purpose-Location Type MDCEV Model 


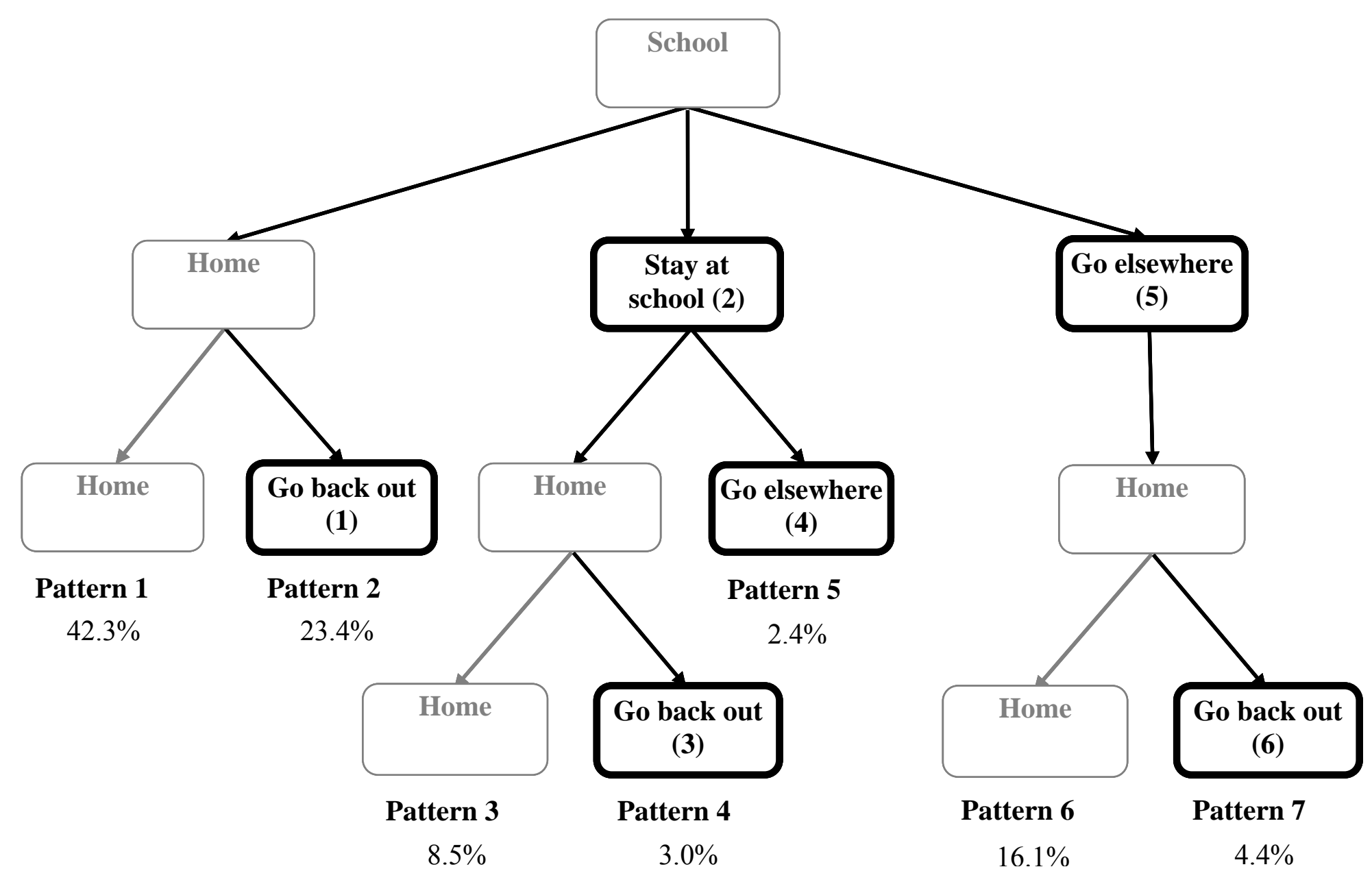

Figure 1. Children's Post-School Patterns and Percentage of Children Choosing Each Pattern 
Table 1. Number and Percentage of Activity Episode Purpose-Location Type at Each Activity Instance

\begin{tabular}{|c|c|c|c|c|c|c|c|c|c|c|c|c|c|}
\hline \multirow{2}{*}{$\begin{array}{l}\text { Activity episode purpose- } \\
\text { location type }\end{array}$} & \multirow{2}{*}{ Total } & \multicolumn{2}{|c|}{$\begin{array}{l}\text { Go back out } \\
(1)\end{array}$} & \multicolumn{2}{|c|}{$\begin{array}{l}\text { Stay at school } \\
(2)\end{array}$} & \multicolumn{2}{|c|}{$\begin{array}{l}\text { Go back out } \\
(3)\end{array}$} & \multicolumn{2}{|c|}{$\begin{array}{c}\text { Go elsewhere } \\
(4)\end{array}$} & \multicolumn{2}{|c|}{$\begin{array}{c}\text { Go elsewhere } \\
\text { (5) }\end{array}$} & \multicolumn{2}{|c|}{$\begin{array}{c}\text { Go back out } \\
(6)\end{array}$} \\
\hline & & Num. & $\begin{array}{l}\% \text { of } \\
\text { type }\end{array}$ & Num. & $\begin{array}{l}\% \text { of } \\
\text { type }\end{array}$ & Num. & $\begin{array}{l}\% \text { of } \\
\text { type }\end{array}$ & Num. & $\begin{array}{l}\% \text { of } \\
\text { type }\end{array}$ & Num. & $\begin{array}{l}\% \text { of } \\
\text { type }\end{array}$ & Num. & $\begin{array}{l}\% \text { of } \\
\text { type }\end{array}$ \\
\hline Org. activities at school & 226 & 38 & 16.8 & 152 & 67.3 & 6 & 2.7 & 4 & 1.8 & 15 & 6.6 & 11 & 4.9 \\
\hline $\begin{array}{l}\text { Org. activities at location other } \\
\text { than school }\end{array}$ & 169 & 95 & 56.2 & -- & -- & 16 & 9.5 & 8 & 4.7 & 30 & 17.8 & 20 & 11.8 \\
\hline Personal business & 235 & 100 & 42.6 & 1 & 0.4 & 10 & 4.3 & 16 & 6.8 & 87 & 37.0 & 21 & 8.9 \\
\hline Rec. at someone else's home & 245 & 91 & 37.1 & -- & -- & 3 & 1.2 & 8 & 3.3 & 131 & 53.5 & 12 & 4.9 \\
\hline Rec. at school & 87 & 32 & 36.8 & 35 & 40.2 & 6 & 6.9 & 1 & 1.1 & 4 & 4.6 & 9 & 10.3 \\
\hline Rec. at other location & 176 & 86 & 48.9 & -- & -- & 10 & 5.7 & 5 & 2.8 & 66 & 37.5 & 9 & 5.1 \\
\hline Social at someone else's home & 115 & 56 & 48.7 & -- & -- & 6 & 5.2 & 6 & 5.2 & 35 & 30.4 & 12 & 10.4 \\
\hline $\begin{array}{l}\text { Social at location other than } \\
\text { someone else's home }\end{array}$ & 111 & 44 & 39.6 & 28 & 25.2 & 6 & 5.4 & 7 & 6.3 & 17 & 15.3 & 9 & 8.1 \\
\hline Childcare & 122 & 4 & 3.3 & 52 & 42.6 & 0 & 0.0 & 1 & 0.8 & 65 & 53.3 & 0 & 0.0 \\
\hline Meals at restaurant & 100 & 53 & 53.0 & -- & -- & 8 & 8.0 & 6 & 6.0 & 24 & 24.0 & 9 & 9.0 \\
\hline $\begin{array}{l}\text { Meals at location other than } \\
\text { restaurant }\end{array}$ & 139 & 29 & 20.9 & 9 & 6.5 & 1 & 0.7 & 10 & 7.2 & 87 & 62.6 & 3 & 2.2 \\
\hline Other & 310 & 84 & 27.1 & 66 & 21.3 & 9 & 2.9 & 14 & 4.5 & 131 & 42.3 & 6 & 1.9 \\
\hline Total & 2035 & 712 & 35.0 & 343 & 16.9 & 81 & 4.0 & 86 & 4.2 & 692 & 34.0 & 121 & 5.9 \\
\hline
\end{tabular}


Table 2. Descriptive Statistics of Activity Episode Purpose-Location Type Participation

\begin{tabular}{|c|c|c|c|c|}
\hline $\begin{array}{l}\text { Activity episode purpose- } \\
\text { location type }\end{array}$ & $\begin{array}{c}\text { Only activity } \\
\text { episode purpose- } \\
\text { location type in } \\
\text { activity instance } \\
(\%)\end{array}$ & $\begin{array}{c}\text { Act. episode } \\
\text { purpose-location } \\
\text { type + other act. } \\
\text { episode purpose- } \\
\text { location types in } \\
\text { act. instance (\%) }\end{array}$ & $\begin{array}{l}\text { Total } \\
\text { num. }\end{array}$ & $\begin{array}{l}\text { Mean duration } \\
\text { in activity } \\
\text { instance (min.) }\end{array}$ \\
\hline $\begin{array}{l}\text { Organized activities at } \\
\text { school }\end{array}$ & 71.7 & 28.3 & 226 & 111.7 \\
\hline $\begin{array}{l}\text { Organized activities at } \\
\text { location other than school }\end{array}$ & 60.9 & 39.1 & 169 & 98.8 \\
\hline Personal business & 50.6 & 49.4 & 235 & 45.1 \\
\hline $\begin{array}{l}\text { Recreation at someone } \\
\text { else's home }\end{array}$ & 37.1 & 62.9 & 245 & 105.7 \\
\hline Recreation at school & 48.3 & 51.7 & 87 & 102.1 \\
\hline Recreation at other location & 35.8 & 64.2 & 176 & 95.5 \\
\hline $\begin{array}{l}\text { Social at someone else's } \\
\text { home }\end{array}$ & 1.7 & 98.3 & 115 & 82.3 \\
\hline $\begin{array}{l}\text { Social at location other than } \\
\text { someone else's home }\end{array}$ & 4.5 & 95.5 & 111 & 69.4 \\
\hline Childcare & 79.5 & 20.5 & 122 & 127.4 \\
\hline Meals at restaurant & 35.0 & 65.0 & 100 & 61.3 \\
\hline $\begin{array}{l}\text { Meals at location other than } \\
\text { restaurant }\end{array}$ & 10.1 & 89.9 & 139 & 32.0 \\
\hline Other & 33.2 & 66.8 & 310 & 111.7 \\
\hline
\end{tabular}


Table 3. Pattern MNL Model

\begin{tabular}{|c|c|c|c|c|c|}
\hline & \multirow{2}{*}{ Constants } & \multicolumn{4}{|c|}{ Child Demographics } \\
\hline & & Grade 5 to 8 & Grade 9 to 12 & Disabled & Overweight \\
\hline \multicolumn{6}{|l|}{ Go home then: } \\
\hline Stay at home (Pattern 1) & -- & -- & -- & -- & -- \\
\hline Go back out (Pattern 2) & $-1.7177(-11.66)$ & -- & $0.3686(2.95)$ & $-0.8343(-2.29)$ & $-0.2407(-2.05)$ \\
\hline \multicolumn{6}{|l|}{ Stay at school then: } \\
\hline Return home and stay home (Pattern 3) & $-2.7536(-19.96)$ & -- & $0.9402(6.67)$ & -- & -- \\
\hline Return home and go back out (Pattern 4) & $-5.0839(-19.05)$ & -- & $0.9402(6.67)$ & -- & $-0.2407(-2.05)$ \\
\hline Go elsewhere (Pattern 5) & $-5.0969(-21.63)$ & -- & $0.9402(6.67)$ & -- & $-0.2407(-2.05)$ \\
\hline \multicolumn{6}{|l|}{ Go elsewhere then: } \\
\hline Return home and stay home (Pattern 6) & $-1.2788(-6.47)$ & $-0.6084(-4.69)$ & -- & -- & -- \\
\hline Return home and go back out (Pattern 7) & $-3.6021(-9.74)$ & $-0.6084(-4.69)$ & -- & -- & $-0.2407(-2.05)$ \\
\hline
\end{tabular}


Table 3 (cont.) Pattern MNL Model

\begin{tabular}{|c|c|c|c|c|c|}
\hline & \multicolumn{5}{|c|}{ Household Demographics } \\
\hline & $\begin{array}{l}\text { Income is } \\
\$ 90,000+\end{array}$ & $\begin{array}{l}\text { Num. of hh } \\
\text { vehicles }\end{array}$ & $\begin{array}{l}\text { Only one child } \\
\text { lives in hh }\end{array}$ & $\begin{array}{c}\text { Num. of } \\
\text { adults in hh }\end{array}$ & $\begin{array}{l}\text { Household } \\
\text { has internet }\end{array}$ \\
\hline \multicolumn{6}{|l|}{ Go home then: } \\
\hline Stay at home (Pattern 1) & -- & $-0.2235(4.62)$ & $-0.2846(2.18)$ & -- & $0.3220(-3.15)$ \\
\hline Go back out (Pattern 2) & $0.3132(2.55)$ & -- & $-0.2846(2.18)$ & -- & -- \\
\hline \multicolumn{6}{|l|}{ Stay at school then: } \\
\hline Return home and stay home (Pattern 3) & -- & $-0.2235(4.62)$ & -- & -- & -- \\
\hline Return home and go back out (Pattern 4) & $0.3132(2.55)$ & -- & -- & -- & -- \\
\hline Go elsewhere (Pattern 5) & $0.3132(2.55)$ & -- & -- & -- & -- \\
\hline \multicolumn{6}{|l|}{ Go elsewhere then: } \\
\hline Return home and stay home (Pattern 6) & -- & -- & -- & $-0.2856(-3.43)$ & -- \\
\hline Return home and go back out (Pattern 7 ) & $0.3132(2.55)$ & -- & -- & $-0.2856(-3.43)$ & -- \\
\hline
\end{tabular}


Table 3 (cont.) Pattern MNL Model

\begin{tabular}{|c|c|c|c|c|c|c|}
\hline & \multicolumn{2}{|c|}{ Household Demographics } & \multirow{2}{*}{$\begin{array}{c}\text { Other's Dem. } \\
\begin{array}{c}\text { Has older } \\
\text { sibling }\end{array} \\
\end{array}$} & \multicolumn{3}{|c|}{ Child's Attitudes } \\
\hline & $\begin{array}{l}\text { Single-family } \\
\text { dwelling unit }\end{array}$ & $\begin{array}{l}\text { Father is prim. } \\
\text { caregiver }\end{array}$ & & $\begin{array}{l}\text { High educ. } \\
\text { ambition }\end{array}$ & $\begin{array}{l}\text { Gifted } \\
\text { program }\end{array}$ & Sociable \\
\hline \multicolumn{7}{|l|}{ Go home then: } \\
\hline Stay at home (Pattern 1) & -- & -- & -- & -- & $-0.3169(2.85)$ & -- \\
\hline Go back out (Pattern 2) & -- & -- & -- & -- & $-0.3169(2.85)$ & $0.5679(5.14)$ \\
\hline \multicolumn{7}{|l|}{ Stay at school then: } \\
\hline Return home and stay home (Pattern 3) & -- & -- & -- & $0.4375(3.20)$ & -- & -- \\
\hline Return home and go back out (Pattern 4) & -- & -- & -- & $0.4375(3.20)$ & -- & $0.5679(5.14)$ \\
\hline Go elsewhere (Pattern 5) & -- & -- & -- & $0.4375(3.20)$ & -- & $0.5679(5.14)$ \\
\hline \multicolumn{7}{|l|}{ Go elsewhere then: } \\
\hline Return home and stay home (Pattern 6) & -- & $0.6683(2.94)$ & -- & -- & -- & -- \\
\hline Return home and go back out (Pattern 7) & 0.8860 (2.79) & -- & $0.4490(2.04)$ & -- & -- & $0.5679(5.14)$ \\
\hline
\end{tabular}


Table 3 (cont.) Pattern MNL Model

\begin{tabular}{|c|c|c|c|c|c|}
\hline & \multicolumn{5}{|c|}{ Environment/Contextual } \\
\hline & $\begin{array}{l}\text { Attends private } \\
\text { school }\end{array}$ & $\begin{array}{l}\text { High quality } \\
\text { neighborhood }\end{array}$ & $\begin{array}{c}\text { Safe } \\
\text { neighborhood }\end{array}$ & $\begin{array}{l}\text { City size over } 1 \\
\text { million }\end{array}$ & $\begin{array}{l}\text { Activity day is } \\
\text { Friday }\end{array}$ \\
\hline \multicolumn{6}{|l|}{ Go home then: } \\
\hline Stay at home (Pattern 1) & -- & -- & -- & -- & -- \\
\hline Go back out (Pattern 2) & $0.6111(3.03)$ & $-0.4251(-2.53)$ & -- & -- & $0.3381(2.80)$ \\
\hline \multicolumn{6}{|l|}{ Stay at school then: } \\
\hline Return home and stay home (Pattern 3) & $0.8662(3.81)$ & -- & -- & -- & -- \\
\hline Return home and go back out (Pattern 4) & $0.8662(3.81)$ & -- & -- & -- & $0.3381(2.80)$ \\
\hline Go elsewhere (Pattern 5) & $0.8662(3.81)$ & -- & $0.7892(2.31)$ & -- & $0.3381(2.80)$ \\
\hline \multicolumn{6}{|l|}{ Go elsewhere then: } \\
\hline Return home and stay home (Pattern 6) & -- & -- & -- & -- & -- \\
\hline Return home and go back out (Pattern 7) & -- & -- & -- & $-0.8951(-3.61)$ & $0.3381(2.80)$ \\
\hline
\end{tabular}


Table 3 (cont.) Pattern MNL Model

\begin{tabular}{|c|c|c|}
\hline & \multicolumn{2}{|c|}{ Other's Activity-Travel Patterns } \\
\hline & $\begin{array}{l}\text { Prim. caregiver } \\
\text { works after sch. }\end{array}$ & $\begin{array}{l}\text { Other caregiver } \\
\text { works after sch. }\end{array}$ \\
\hline \multicolumn{3}{|l|}{ Go home then: } \\
\hline Stay at home (Pattern 1) & $-0.6858(7.10)$ & -- \\
\hline Go back out (Pattern 2) & $-0.6858(7.10)$ & -- \\
\hline \multicolumn{3}{|l|}{ Stay at school then: } \\
\hline Return home and stay home (Pattern 3) & -- & -- \\
\hline Return home and go back out (Pattern 4) & -- & $0.6441(2.36)$ \\
\hline Go elsewhere (Pattern 5) & -- & -- \\
\hline \multicolumn{3}{|l|}{ Go elsewhere then: } \\
\hline Return home and stay home (Pattern 6) & -- & -- \\
\hline Return home and go back out (Pattern 7) & -- & -- \\
\hline
\end{tabular}


Table 4. Activity Episode Purpose-Location Type MDCEV Model

\begin{tabular}{|c|c|c|c|c|c|c|}
\hline & \multicolumn{4}{|c|}{ Child Demographics } & \multicolumn{2}{|c|}{ Household Demographics } \\
\hline & Grade $k$ to 4 & Caucasian & Hispanic & $\begin{array}{l}\text { African- } \\
\text { American }\end{array}$ & $\begin{array}{l}\text { Income is } \\
\$ 90,000+\end{array}$ & $\begin{array}{l}\text { Household } \\
\text { size }\end{array}$ \\
\hline Organized activities at school & -- & -- & -- & -- & -- & -- \\
\hline $\begin{array}{l}\text { Organized activities at location other } \\
\text { than school }\end{array}$ & -- & $0.3814(2.68)$ & -- & -- & -- & -- \\
\hline Personal business & $0.3703(2.38)$ & $0.4358(2.92)$ & -- & -- & -- & $0.2087(3.16)$ \\
\hline Recreation at someone else's home & $0.4151(3.40)$ & -- & -- & -- & -- & -- \\
\hline Recreation at school & $0.4151(3.40)$ & $0.5849(2.47)$ & -- & -- & -- & -- \\
\hline Recreation at other location & $0.4151(3.40)$ & $0.3814(2.68)$ & $1.0154(3.39)$ & -- & -- & -- \\
\hline Social at someone else's home & -- & -- & -- & -- & -- & -- \\
\hline $\begin{array}{l}\text { Social at location other than someone } \\
\text { else's home }\end{array}$ & -- & -- & -- & -- & -- & -- \\
\hline Childcare & $2.3343(8.99)$ & -- & -- & -- & -- & -- \\
\hline Meals at restaurant & -- & -- & -- & $-1.3555(-4.12)$ & $0.5503(2.46)$ & -- \\
\hline Meals at location other than restaurant & $0.8511(4.44)$ & -- & -- & -- & -- & $-0.2452(-2.89)$ \\
\hline Other & -- & -- & -- & -- & -- & -- \\
\hline
\end{tabular}


Table 4 (cont.) Activity Episode Purpose-Location Type MDCEV Model

\begin{tabular}{|c|c|c|c|c|c|c|}
\hline & \multicolumn{4}{|c|}{ Household Demographics } & \multicolumn{2}{|c|}{ Others' Demographics } \\
\hline & Only child & $\begin{array}{l}\text { Household } \\
\text { has internet }\end{array}$ & $\begin{array}{l}\text { Single-family } \\
\text { dwelling unit }\end{array}$ & $\begin{array}{c}\text { Grandparent } \\
\text { is prim. } \\
\text { caregiver }\end{array}$ & $\begin{array}{l}\text { Age of prim. } \\
\text { caregiver }\end{array}$ & $\begin{array}{l}\text { Has younger } \\
\text { sibling }\end{array}$ \\
\hline Organized activities at school & -- & $0.4974(2.99)$ & -- & -- & -- & -- \\
\hline $\begin{array}{l}\text { Organized activities at location other } \\
\text { than school }\end{array}$ & -- & $0.4974(2.99)$ & $0.4523(2.63)$ & -- & -- & -- \\
\hline Personal business & $0.5404(2.46)$ & -- & -- & -- & -- & -- \\
\hline Recreation at someone else's home & -- & -- & -- & -- & $-0.0388(-3.69)$ & $-0.3510(-2.38)$ \\
\hline Recreation at school & -- & -- & -- & -- & -- & -- \\
\hline Recreation at other location & -- & -- & $0.4523(2.63)$ & $1.0908(2.75)$ & -- & -- \\
\hline Social at someone else's home & -- & -- & -- & -- & -- & -- \\
\hline $\begin{array}{l}\text { Social at location other than someone } \\
\text { else's home }\end{array}$ & -- & -- & -- & -- & -- & -- \\
\hline Childcare & -- & -- & -- & -- & -- & -- \\
\hline Meals at restaurant & -- & -- & -- & -- & -- & -- \\
\hline Meals at location other than restaurant & -- & -- & -- & -- & -- & -- \\
\hline Other & -- & -- & -- & -- & -- & -- \\
\hline
\end{tabular}


Table 4 (cont.) Activity Episode Purpose-Location Type MDCEV Model

\begin{tabular}{|c|c|c|c|c|c|}
\hline & \multirow{2}{*}{$\begin{array}{c}\text { Others' Dem. } \\
\begin{array}{c}\text { Has older } \\
\text { sibling }\end{array}\end{array}$} & \multicolumn{4}{|c|}{ Child's Attitudes } \\
\hline & & $\begin{array}{l}\text { High educ. } \\
\text { ambition }\end{array}$ & Gifted program & $\begin{array}{l}\text { Special } \\
\text { education }\end{array}$ & Sociable \\
\hline Organized activities at school & -- & -- & -- & -- & $0.3037(2.00)$ \\
\hline $\begin{array}{l}\text { Organized activities at location other than } \\
\text { school }\end{array}$ & $0.4886(3.82)$ & -- & -- & -- & $0.3037(2.00)$ \\
\hline Personal business & -- & $-0.3162(-1.98)$ & -- & $0.7311(2.91)$ & -- \\
\hline Recreation at someone else's home & -- & $-0.5567(-4.04)$ & -- & -- & -- \\
\hline Recreation at school & -- & -- & -- & -- & -- \\
\hline Recreation at other location & $0.4886(3.82)$ & -- & -- & -- & -- \\
\hline Social at someone else's home & -- & $-0.5567(-4.04)$ & -- & -- & -- \\
\hline $\begin{array}{l}\text { Social at location other than someone } \\
\text { else's home }\end{array}$ & -- & -- & -- & -- & -- \\
\hline Childcare & -- & -- & $-1.17(-3.98)$ & -- & -- \\
\hline Meals at restaurant & -- & -- & -- & -- & -- \\
\hline Meals at location other than restaurant & -- & -- & -- & -- & -- \\
\hline Other & -- & -- & -- & -- & -- \\
\hline
\end{tabular}


Table 4 (cont.) Activity Episode Purpose-Location Type MDCEV Model

\begin{tabular}{|c|c|c|c|c|c|}
\hline & \multicolumn{3}{|c|}{ Environment/Contextual } & \multicolumn{2}{|c|}{ Others' Activity-Travel Patterns } \\
\hline & $\begin{array}{l}\text { Child attends } \\
\text { private School }\end{array}$ & $\begin{array}{l}\text { Metropolitan } \\
\text { area county }\end{array}$ & $\begin{array}{l}\text { Activity day is } \\
\text { Friday }\end{array}$ & $\begin{array}{l}\text { Prim. caregiver } \\
\text { works after sch. }\end{array}$ & $\begin{array}{l}\text { Other caregiver } \\
\text { works after sch. }\end{array}$ \\
\hline Organized activities at school & -- & -- & $-0.9951(-5.66)$ & -- & $0.3779(2.95)$ \\
\hline $\begin{array}{l}\text { Organized activities at location other than } \\
\text { school }\end{array}$ & $0.8041(3.27)$ & -- & $-0.9951(-5.66)$ & -- & $0.3779(2.95)$ \\
\hline Personal business & -- & -- & -- & -- & -- \\
\hline Recreation at someone else's home & -- & -- & -- & $-0.7356(-4.88)$ & -- \\
\hline Recreation at school & -- & -- & -- & -- & -- \\
\hline Recreation at other location & -- & -- & -- & -- & -- \\
\hline Social at someone else's home & -- & -- & -- & -- & -- \\
\hline $\begin{array}{l}\text { Social at location other than someone } \\
\text { else's home }\end{array}$ & -- & -- & -- & -- & -- \\
\hline Childcare & -- & $0.9745(3.05)$ & -- & $1.1073(4.55)$ & -- \\
\hline Meals at restaurant & -- & $0.5961(3.21)$ & -- & -- & -- \\
\hline Meals at location other than restaurant & -- & $0.5961(3.21)$ & -- & -- & -- \\
\hline Other & -- & -- & -- & -- & -- \\
\hline
\end{tabular}


Table 4 (cont.) Activity Episode Purpose-Location Type MDCEV Model

\begin{tabular}{|c|c|c|c|c|}
\hline & \multicolumn{4}{|c|}{ Activity Instance } \\
\hline & Stay at school (2) & Go back out (3) & Go elsewhere (5) & Go back out (6) \\
\hline Organized activities at school & $2.4295(11.34)$ & -- & $-1.1138(-3.65)$ & $1.0548(2.85)$ \\
\hline Organized activities at location other than school & -- & -- & $-1.2581(-5.74)$ & $0.7373(2.51)$ \\
\hline Personal business & -- & $0.9103(3.04)$ & -- & $0.9617(3.43)$ \\
\hline Recreation at someone else's home & -- & -- & -- & -- \\
\hline Recreation at school & $1.2830(4.79)$ & -- & $-2.2594(-4.27)$ & $0.9124(2.28)$ \\
\hline Recreation at other location & -- & -- & -- & -- \\
\hline Social at someone else's home & -- & -- & -- & $0.9459(2.77)$ \\
\hline Social at location other than someone else's home & $0.5598(2.14)$ & -- & $-1.2030(-4.28)$ & -- \\
\hline Childcare & $4.0500 \quad(8.09)$ & -- & $2.3929(5.05)$ & -- \\
\hline Meals at restaurant & -- & -- & $-0.9432(-3.82)$ & -- \\
\hline Meals at location other than restaurant & -- & -- & $0.9596(4.98)$ & -- \\
\hline Other & -- & -- & -- & -- \\
\hline
\end{tabular}


Table 4 (cont.) Activity Episode Purpose-Location Type MDCEV Model

\begin{tabular}{|c|c|c|}
\hline & $\begin{array}{l}\text { Baseline Preference } \\
\text { Constants }\end{array}$ & Satiation Parameters \\
\hline Organized activities at school & $-1.8430(-7.69)$ & $1.0000 \quad(--)$ \\
\hline Organized activities at location other than school & $-1.8216(-6.98)$ & $0.9681(3.07)$ \\
\hline Personal business & $-1.4574 \quad(-4.09)$ & $0.8666(8.89)$ \\
\hline Recreation at someone else's home & $1.4577 \quad(3.28)$ & $0.9142(6.50)$ \\
\hline Recreation at school & $-1.8913(-7.95)$ & 0.9435 (3.34) \\
\hline Recreation at other location & $-1.5770(-8.17)$ & $0.9109(6.10)$ \\
\hline Social at someone else's home & $-0.8837(-7.20)$ & 0.8756 (6.51) \\
\hline Social at location other than someone else's home & $-0.9782(-6.89)$ & $0.9071(5.34)$ \\
\hline Childcare & $-6.0873(-10.24)$ & $0.9780(2.32)$ \\
\hline Meals at restaurant & $-1.1416 \quad(-5.03)$ & $0.8619(6.36)$ \\
\hline Meals at location other than restaurant & $-1.1658 \quad(-2.92)$ & $0.6978(11.19)$ \\
\hline Other & -- & $0.8576(11.30)$ \\
\hline
\end{tabular}

